\title{
La migración transnacional y su incidencia en las pautas de crianza ${ }^{1}$
}

\section{Transnational Migration and its Impact on Parenting Patterns}

\author{
María Constanza Gutiérrez Aldana² \\ Auxiliares de investigación ${ }^{3}$
}

\section{Resumen}

El presente artículo muestra los resultados de la investigación Implicaciones afectivas y económicas del migrante transnacional y su familia. Para dar respuesta a la investigación se planteó como objetivo general identificar los a spectos que inciden y los cambios en los sistemas familiares en cuanto a relaciones afectivas, situación económica del migrante y su familia. Como objetivos específicos se planteó: 1. Crear un paralelo entre la situación económica del migrante y su familia antes y después de la migración. 2. Identificar las relaciones afectivas familiares entre el migrante y su familia antes y durante la migración y 3 . Identificar el funcionamiento de las dinámicas familiares: (roles y funciones) entre el migrante y su familia antes y durante la migración.

La investigación se centró en el paradigma fenomenológico - hermenéutico. Para la recolección de la información se utilizó la entrevista semiestructurada y la encuesta, se entrevistaron 16 familias, el padre o la madre que hubiera migrado, en un tiempo no menor a un año y a un integrante de la familia residente en Colombia. La encuesta se aplicó a la persona migrante en temas relacionados con el aspecto socio- económico.

En lo referente a las normas y pautas de crianza de los hijos cuando es el padre quien migra, se generan cambios en la autoridad, la toma de decisiones, el rol paterno, la proveeduría, éstas funciones las comienza a ejercer la madre que queda a cargo de los hijos.

Palabras clave: Familia. Rol; Migración; Relaciones afectivas; Autoridad; Pautas de crianza.
This paper presents the results of the research Affective and economic implications of the transnational migrant and his or her family. As a general objective, it was proposed to identify the aspects that affect the family systems as well as its changes in relation to affective relationships, economic situation of the migrant and his or her family. Specific objectives were: 1 . To make a comparison between the economic situation of the migrant and his or her family before and after migration. 2. To identify emotional relationships between the migrant and his or her family before and during the migration; and 3. To identify the functioning of family dynamics: (roles and functions) between the migrant and his or her family before and during the migration.

The research focused on the phenomenological hermeneutic paradigm. Semi-structured interview and survey were used for the collection of data, 16 families were interviewed, the father or mother who had migrated, in a time not less than one year and a member of the family residing in Colombia. The survey applied to the migrant is related to the socio-economic aspect.

With regard to norms and parenting patterns, when the father is who migrates, changes in authority, decision making, paternal role and handling money arise, and these functions are are assumed by the mother who is left in charged of the children.

Keywords: Family role. Migration. Relationships. Authority and breeding patterns.

Artículo resultado de investigación.

${ }^{2}$ Trabajadora Social. Magister en Desarrollo Social y Educativo. Especialista en Gestión para el Desarrollo Empresarial. Docente de la Fundación Universitaria Monserrate -Unimonserrate. Investigadora Social. E-mail: coordinacionpracticatsd@unimonserrate.edu.co

${ }^{3}$ Auxiliares de investigación: Karen Johanna Quintero Martín. Nancy Paola Jiménez Pulido. Paula Alejandra Triana Hernández. Lorena Jineth Urrea Ballesteros. Wilson Alfredo Vargas Medina. 


\section{Introducción}

El presente artículo muestra los resultados de la investigación Implicaciones afectivas y económicas del migrante transnacional y su familia, la cual se realizó en el Programa de Trabajo Social de la Fundación Universitaria Monserrate con los estudiantes de investigación, requisito para optar el título de Trabajadores Sociales como un proceso formativo desde 2014 y 2015 y en el interés de aportar a la línea del Programa Familia Desarrollo Humano y Social en cuanto a las familias transnacionales, como una nueva forma de construcción de familia desde la distancia, así como cuando uno de sus miembros, en el caso de la investigación, migra: el padre o la madre buscando mejores condiciones laborales. Para el desarrollo del artículo se ha tomado una de las categorías de análisis, denominada dinámica familiar y las subcategorías distribución de los roles, pautas de crianza, en el tema de la autoridad y la toma de decisiones, durante la migración y como la ausencia de uno de los padres genera cambios.

Para dar respuesta a la investigación se planteó como objetivo general identificar los aspectos que inciden y los cambios existentes en los sistemas familiares, en cuanto a relaciones afectivas y la situación económica del migrante y su familia.

La investigación se desarrolló con 16 personas, bajo el criterio de ser padre o madre migrante hacia otro país, durante un periodo de un año como mínimo; los entrevistados viajaron a España, Estados Unidos, Chile, en un promedio de edades entre 20 y 30 años, una formación de un $25 \%$ básica secundaria, seguido de un $25 \%$ de bachillerato completo y un $25 \%$ de técnico y los motivos del viaje $62 \%$ problemas económicos un $19 \%$ falta de oportunidades laborales y un $9 \%$ estudio.

Las gráficas muestran las razones que llevaron a migrar a uno de los padres y el nivel educativo.
¿CUÁL ES SU NIVEL EDUCATIVO?

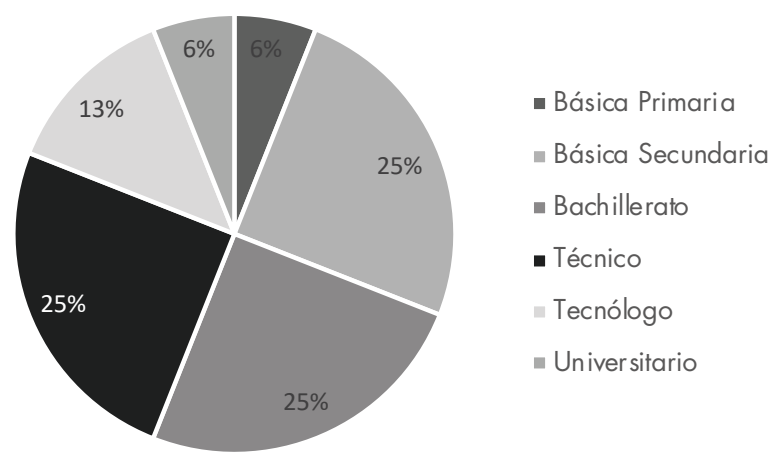

Fuente: Encuesta realizada al padre o madre que migró.

¿CUÁLES FUERON LAS RAZONES QUE LO LLEVARON A MIGRAR?

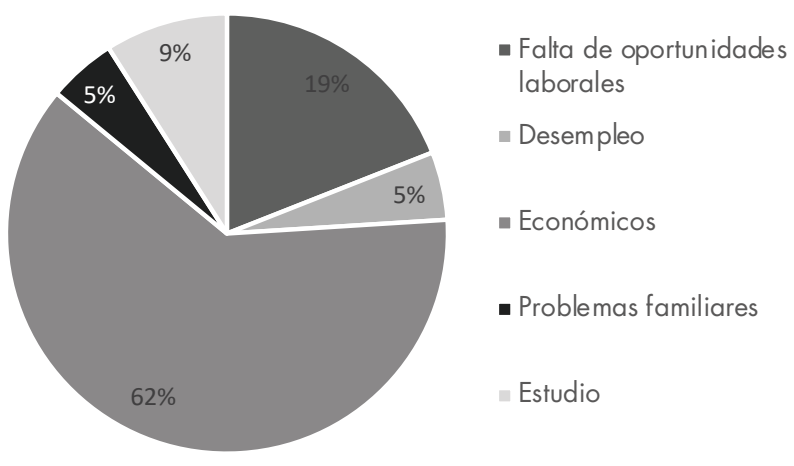

Fuente: Encuesta realizada al padre o madre que migró.

Las familias transnacionales como un fenómeno que perturba visiblemente las relaciones afectivas, las dinámicas de las familias, conceptos que ya se han mencionado con anterioridad; además que permite identificar esos factores que han generado un cambio en su estructura y que está estrechamente relacionado con la migración de uno o varios miembros de una familia. Razón por la cual se haya la necesidad de ahondar frente a la perspectiva trasnacionalismo,

Guarnizo, (2006) plantea que los migrantes no necesariamente rompen sus lazos identitarios, sociales, políticos, culturales y económicos con sus tierras de origen. Estas relaciones se mantienen a larga distancia, haciendo posible que los que se fueron sigan participando en procesos familiares 
y comunitarios a niveles múltiples con los que se quedaron, haciendo a estos últimos, parte activa del vivir transnacional (p.83).

Esta investigación parte del interés de la investigadora principal por continuar profundizando en el tema de la migración internacional y las familias transnacionales, tema que no ha sido muy explorado en el Programa de Trabajo Social y que es importante ya que el fenómeno de la migración aporta a la formación de los profesionales y se presenta como un nuevo panorama para la intervención con las familias transnacionales, las relaciones afectivas, los sentimientos y los cambios en los roles.

\section{Métodos y materiales}

La investigación se aborda desde el paradigma fenomenológico hermenéutico, el cual según González (2011), "se busca reconocer la diversidad, comprender la realidad; construir sentido a partir de la comprensión histórica del mundo simbólico; de allí el carácter fundamental de participación y el conocimiento del contexto como condición para hacer la investigación" ( $p$, 30). El paradigma busca comprender e indagar las circunstancias o situaciones que conllevaron a los miembros e integrantes del grupo familiar a migrar de su país de origen, analizando este fenómeno desde las posturas personales, familiares y contextuales.

Para la investigación el enfoque utilizado es de carácter mixto, dando un mayor énfasis al enfoque cualitativo, ya que según Hernández, Fernández y Baptista (2008), cuando se logran combinar aspectos de la investigación cualitativa y cuantitativa, allí se resume y se organiza la información de manera integral permitiendo utilizar técnicas como la observación, entrevista y la encuesta, que nos permite evaluar situaciones del fenómeno de la migración.
Según (Hernández, et al., 2003), El enfoque cuantitativo se fundamenta en un esquema deductivo y lógico, busca formular preguntas de investigación e hipótesis para posteriormente probarlas, utiliza el análisis estadístico, es reduccionista y pretende generalizar los resultados mediante muestras representativas, la recolección de información la realiza a través de las encuestas, confía en la medición estandarizada. (p 23).

De acuerdo con lo planteado por Hernández, el enfoque cuantitativo permitió establecer un paralelo de la situación económica del migrante antes de viajar y el buscar nuevas oportunidades mejoró sus ingresos y el de su familia, así como también caracterizar la población que viajó en cuanto a edad, nivel educativo y motivos por los cuales decidieron migrar.

El enfoque cualitativo permite identificar las diferentes formas de organización familiar, la dinámica familiar, los roles, pautas de crianza, los medios tecnológicos para comunicarse en la distancia, permite comprender las relaciones afectivas, sentimientos, emociones y el lenguaje; mientras que el método cuantitativo permite estudiar el aspecto económico del migrante en el momento de la migración y si el migrar mejoró la situación económica de su familia.

El tipo de investigación es descriptiva la cual, según Hernández, et al., (2003), "permiten describir situaciones, eventos y hechos, buscan especificar las propiedades, las características y los perfiles importantes de personas, grupos, comunidades o cualquier fenómeno que se someta a un análisis" (p. 117), para esta investigación es importante lograr describir el fenómeno de la migración y el impacto en la dinámica familiar y formas de crianza.

La muestra poblacional de esta investigación fueron 16 familias que residen en la ciudad de Bogotá, con un padre o madre que migró en un 
período no menor a un año; las edades en el momento de la migración estaban entre los 20 y 30 años de edad y los principales países de destino fueron: Argentina, Chile, España, Estados Unidos.

Para la recolección de la información se utilizó la entrevista semi-estructurada y la encuesta; la primera, "parte de un guion de temas a tratar como carta de navegación que permite abordar puntos esenciales relativos al tema central de la investigación" (Cifuentes, 2011, p. 85), para este artículo la categorías de análisis denominada dinámica familiar y las subcategorías anunciadas y la segunda, es decir la encuesta, según (Hernández, et al., 2003)

es el instrumento más utilizado para recolectar los datos y consiste en un conjunto de preguntas, básicamente se consideran dos tipos de preguntas cerradas y abiertas. Las preguntas cerradas contienen categorías o alternativas de respuesta que han sido delimitadas, las preguntas pueden ser dicotómicas (dos alternativas de respuesta) o incluir varias alternativas. (p. 391)

Las entrevistas se realizaron a 16 personas que migraron a diferentes países y a 16 personas que se quedaron en su país de origen, familiares de los migrantes, para un total de 32 entrevistados. El objetivo de las entrevistas fue conocer la percepción y testimonios del migrante y su familia frente a la dinámica familiar, las tipologías de familia y las relaciones familiares.

Para el aspecto económico se realizaron 16 encuestas al padre o madre que migró, con el fin de conocer cómo era la situación económica de las familias en el antes y el durante de la migración y si el migrar aportó a mejorar las condiciones económicas de la familia.

\section{Resultados}

Una vez realizadas las 32 entrevistas de acuerdo con las categorías previamente establecidas en el proyecto de investigación, y luego de aplicar la téc- nica de triangulación que se refiere a los resultados cualitativos y cuantitativos obtenidos entre las categorías, motivos de migración, formas de organización familiar, dinámica familiar y relaciones afectivas, que permiten tener una visión desde diferentes ángulos y posiciones, se logra comprender el fenómeno de las familias transnacionales y los cambios en los roles de cada integrante del sistema familiar.

(Ojeda, 2005, Bryceson y Vuorela, 2007, Pare1la, 2007, citados por Cienfuegos, 2011), plantean el concepto de familia transnacional como:

El fenómeno de desterritorialización de la familia se le conoce como familia transnacional o a distancia, definida como la práctica de conformación de unidades familiares separadas por la distancia territorial una parte o la mayor parte del tiempo, que se ven sustentadas a través de un conjunto de intercambios materiales y simbólicos -económicos, sociales y demográficos- que garantizan su reproducción cotidiana en un sentido amplio, incluso a pesar de las posibles asimetrías existentes entre los dos o más países en los cuales se sitúa. En ella está establecido también un haz de obligaciones mutuas que permiten que sus miembros se sientan pertenecientes a una unidad. (p, 164)

Por lo anterior se muestra que a pesar de la distancia que implica el fenómeno de la migración, los miembros de las familias se sienten identificados con su grupo familiar, bien sea por las razones que han llevado a la persona que migra, por ejemplo, por lo económico, lo social, entre otros.

(Ariza y D'Aubeterre 2009, citados por Cienfuegos, 2011), plantean el concepto de familia trasnacional, así:

En las últimas décadas, la familia transnacional viene a desestabilizar este supuesto con la 
construcción de espacios sociales transnacionales y la mantención de vínculos a la distancia: "Se trata de familias disociadas espacialmente, pero enlazadas afectivamente; no comparten una misma vivienda, no viven bajo un mismo techo, pero tienen un ingreso común, así como un proyecto de vida colectivo". El distanciamiento espacial en la vivencia del lazo conyugal abre un espacio de incertidumbre en el horizonte familiar y replantea las fronteras habituales de la convivencia del grupo (...) trastoca al mismo tiempo dimensiones cruciales de la vida familiar como la socialización y educación de los hijos, el ejercicio de la paternidad y maternidad, la afectividad, la sexualidad y hasta las pautas de sociabilidad, que han de buscar -cuando se pueda- cauces alternativos de expresión. (p, 166)

Según el párrafo anterior, el fenómeno de la migración separa físicamente y/o territorialmente a las familias, pero afectivamente siempre estarán unidas; sin embargo, el fenómeno va a incidir en los diferentes roles de los grupos familiares: paterno, materno, fratría, conyugalidad, los cuales serán expuestos más adelante.

Se evidencia que como consecuencia de la distancia en la que se encuentra la persona que migra y sin permitir un contacto físico con los miembros de la familia, no solo se genera el cambio de roles en el hogar, sino que también afecta el vínculo entre padre e hijos, ya que este no se encuentra presente en el desarrollo de su ciclo vital, lo cual hace que sus hijos vean más cercana a la persona que está de manera presencial, bien sea en la familia nuclear, extensa, monoparental o recompuesta, teniendo en cuenta que en las entrevistas realizadas, el promedio en años de migración es aproximadamente de 12 años, esto da cuenta de que efectivamente el ciclo vital en el que se encontraban los hijos cuando uno de los dos padres migró era el escolar, y que por lo tanto luego de los años los roles cambiado.

Expuesto lo anterior, (Estremero y García, s,f.) definen las etapas del ciclo vital de la familia de la siguiente manera:

La Constitución de la pareja: Con la formación de una pareja queda constituido un nuevo sistema, que será el inicio de una nueva familia. Este nuevo sistema/pareja tendrá características nuevas y propias. (...) (p. 19-20).

El Nacimiento y crianza: El nacimiento de un hijo crea muchos cambios tanto en la relación de pareja como en toda la familia. Aparecen nuevos roles y funciones: madre, padre, función materna y función paterna); y con ellos los de la familia extensa: abuelos, tíos, primos, etc. (...) (p. 20).

Hijos en edad escolar: Esta es una etapa crucial en la evolución de la familia. Es el primer desprendimiento del niño del seno familiar. Se unirá a una nueva institución con maestros y compañeros y realizará nuevas actividades fuera del hogar. (...) (p. 20).

La adolescencia: Es una etapa de grandes crisis para la mayoría de los individuos y las familias. Se producen grandes cambios en todos los integrantes del núcleo familiar y en la relación de éstos con el exterior. (...) (p. 20-21).

Casamiento y salida de los hijos del hogar: Esta nueva etapa está marcada por la capacidad de la familia de origen para desprenderse de sus hijos y de incorporar a nuevos individuos como el cónyuge y la familia política. Los hijos entrarán en una nueva etapa donde deberán formar su propia familia, para poder continuar el ciclo vital. (...) (p. 21).

Pareja en edad madura: La pareja se enfrentará a nuevos desafíos. Por un lado, el reencuentro entre ellos, dado por la salida de los hijos del hogar y por el cese laboral. De las 
características de este encuentro dependerá que la pareja continúe unida o no. Por otro lado, deberán afrontar cambios no solo en lo individual sino también a nivel familiar. (...) (p.21).

Ancianidad: Cada uno de los integrantes sufrirá cambios a nivel corporal (mayor fragilidad, enfermedades crónicas, etc.) y/o emocional. (...) (p. 21).

De acuerdo con los hallazgos encontrados en las entrevistas realizadas y los diferentes análisis, a continuación, se relaciona el marco teórico de roles según diferentes autores con los resultados arrojados por la investigación, teniendo en cuenta que los roles determinados en la categorización de la investigación y reflejados en las entrevistas fueron el rol de paterno, materno, proveeduría, fratria, filiación o autoridad familiar y conyugalidad.

Para desarrollar ampliamente la tesis formulada, es necesario conocer explícitamente los cambios de roles con relación a las pautas de crianza de los hijos, es así como se presenta a continuación una breve descripción de lo que algunos autores definen acerca de cada rol, y a su vez se exponen de manera general los cambios que presentan esos roles cuando uno de los padres migra.

\section{Rol de Paternidad.}

Según Rivera y Ceciliano, (2004) refieren que el rol de paternidad es:

Una construcción social, subjetiva y cultural. En la actualidad, el padre como figura que provee no es suficiente para satisfacer las necesidades emocionales de los niños, las niñas y las mujeres, y en muchos casos la percepción que se tiene de un padre presente significa lo mismo que un padre ausente, mientras este sea un buen proveedor. La nueva paternidad habla de un involucramiento más afectivo y activo; es decir, una paternidad que permita involucrarse afectivamente con el niño o la niña y participar responsablemente en todas las actividades de los menores, sin necesidad de feminizarse; pues de la masculinidad pueden rescatar elementos positivos para el ejercicio de una paternidad responsable. (p. 33)

Algunos de los casos estudiados muestran que la persona que migra en su mayoría es el padre o en su defecto quien estando en Colombia ejerce el rol de proveeduría, según los resultados esto ocurre dado que en Colombia el padre es quien lleva la provisión para el sostenimiento del hogar, por tanto, su necesidad e interés de generar mayores ingresos y promover una mejor calidad de vida a sus hijos y su familia lo llevan a tomar la decisión de migrar.

La información recolectada por medio de las técnicas e instrumentos demuestran que quien ejerce el rol de proveeduría ejerce a su vez el rol de autoridad y que cuando el padre o la madre se encuentra en Colombia, es respetado y obedecido por su núcleo familiar, siendo éste el caso de la mayoría de familias entrevistadas, los padres eran los proveedores de los hogares, y a su vez eran la autoridad, aunque consultaban los temas con sus esposas y eran apoyados por ellas, la figura que representaba la autoridad en los hogares frente a sus hijos eran los padres.

Por otro lado, (Puyana y Mosquera 2001, citado por Micolta, (2002) nos dan a entender desde otra perspectiva el significado de paternidad:

La paternidad consagra la hombría, representa una transformación total, es un proceso de reconstrucción de la identidad masculina que comprende todas las dimensiones de la hombría: la natural, la doméstica, la pública y la trascendental. La natural, por cuanto es una prueba de su propia virilidad, la doméstica porque lo une a una pareja, la pública por el 
reconocimiento social que se ofrece y la trascendental porque permite la continuidad de la vida. (p. 166)

Dado el concepto anterior y basado en los resultados de las entrevistas, la hombría de la que habla el autor está dada sobre todo en términos económicos, es decir, la provisión del hogar y esto es lo que le da el reconocimiento en la sociedad y establece su virilidad frente a sus hijos y su esposa.

Infortunadamente con el pasar de los años, el concepto de paternidad toma otro significado, las prioridades cambian y cuando ocurre un suceso como la migración esto se corrobora, pues los padres migran en búsqueda de mejores oportunidades laborales y económicas, pero como se ha expuesto en el desarrollo de la ponencia, el aspecto económico no es el único factor importante $y$ trascendental en la vida familiar, hace falta el afectivo.

A continuación, se relaciona uno de los tantos testimonios recolectados en la aplicación de las entrevistas aplicadas en esta investigación.

Uno de los entrevistados que migró a Argentina durante un año y cuatro meses, da respuesta a la siguiente pregunta: ¿Cómo se establecían las normas en su familia y quién las determinaba?

Yo nunca quise imponer nada en mi casa, pero de una forma u otra las determinaba yo, creo que eso es porque soy mayor que Claudia; entonces tenía un poco más de experiencia en muchas cosas, ahora yo trato de seguir manejando las cosas, pero desde acá es más difícil y por eso ahora mi esposa se ha encargado de las cositas que van saliendo con el diario vivir. (Entrevistado 2015)

Con su partida y el proceso de migración, su rol paterno sufrió cambios notorios y trascendentales en el hogar, tales como:

Los hijos le pierden respeto y obediencia ya que el padre no tiene forma de verificar y hacer cumplir las normas, pues los entrevistados manifestaron que la forma de hacer cumplir los reglamentos y de corregir a los hijos era: Para los pequeños, la correa y para los más grandes, el quitarles gustos y privilegios, lo cual se le dificultó al padre desde la distancia en que se encontraba.

La distancia evidentemente se deteriora la comunicación; antes de la migración dedicaban horas y días para hablar de un tema con los hijos, pero después de la migración son solo algunos minutos contados, sin embargo, muchas familias aprovechan las redes sociales como Skype y Facebook para mantener la comunicación. De acuerdo a las entrevistas realizadas, se evidencia que la mayoría de los padres migraron en una de las etapas más importantes del ciclo vital de la familia: la adolescencia de los hijos, al respecto (Estremero y García, et,al., s,f), indican:

La adolescencia es una etapa de grandes crisis para la mayoría de los individuos y las familias. Se producen grandes cambios en todos los integrantes del núcleo familiar y en la relación de éstos con el exterior. El adolescente sufre una gran crisis de identidad. (...) Es una etapa de grandes turbulencias emocionales para el adolescente que atraviesa el desafío de transformarse en adulto (dejando la imagen idealizada de los padres de la infancia), definir su identidad sexual y conquistar cierto grado de autonomía en lo emocional y mental. (...) La ausencia de límites hace que el adolescente se sienta solo, desamparado y da lugar a que aparezcan conductas de riesgo (violencia, embarazos no deseados, drogas, etc.) con el propósito de captar la atención de sus padres. (p. 21)

En lo que respecta a las relaciones afectivas entre 
el padre y sus hijos, no se reflejan muchos cambios, ya que la mayoría de encuestas dejan ver que por temas laborales y de género (masculino) tanto antes como después de la migración, las demostraciones de afecto eran limitadas, los padres en su mayoría se dedicaban a llevar la provisión a casa y a corregir a los hijos, el tema afectivo se le otorgaba a las madres y es en este sentido en el que afirmamos que los resultados tienen gran relación con la teoría, no es suficiente la figura de padre como proveedor, es necesario establecer lazos fuertes afectivos; seguramente si esos padres que migraron hubiesen tenido sólidas demostraciones de afecto con sus hijos no se hubiera visto tan afectado su rol paterno con su partida.

Pribilsky (citado por Sánchez, López y Palacio, 2013), nos da a entender que:

La relación materno y paterno filial se traslada, a un espacio social trasnacional, en el cual fluyen y circulan sentimientos, emociones y recursos económicos que mantienen los vínculos entre quienes permanecen en el país de origen y aquellos que se encuentran en el destino. ( $p, 165)$

En este sentido y de acuerdo con el análisis de las entrevistas aplicadas, la mayoría de casos muestran que el padre al migrar presenta dificultades para mantener las relaciones afectivas, sentimientos y emociones con sus hijos, dada la ausencia física que impide estar presente en el acompañamiento del desarrollo físico y emocional, pues no pueden observar día a día los comportamientos, actitudes y la formación académica de los hijos, lo que afecta significativamente esos vínculos con sus hijos, como lo afirma el autor.

\section{El rol de maternidad}

Es definido por Rivera y Ceciliano et al, (2004) como:
La maternidad, es un constructo social y simbólico que adquiere diferentes significados en diferentes contextos socio - históricos. Siempre ha estado en el centro del rol femenino; ya que ésta implica la realización de actividades relacionadas con la reproducción y la crianza de los hijos. (p.28)

Teniendo en cuenta el rol de paternidad definido y expuesto en párrafos anteriores en los que se afirma que de acuerdo con las entrevistas realizadas la mayoría de los migrantes son los padres y que esa migración genera cambios sobre todo en lo que tiene que ver con la autoridad, es precisamente el rol materno el que asume esta función.

Dado que el motivo de migración que prima es el económico, las entrevistas dejan ver que muchas de las madres que se quedan en Colombia, durante los primeros meses deben tener el rol de proveedoras, mientras su pareja logra estabilizarse y cumplir este rol a la distancia, por tanto, asumir el rol de proveeduría implica un esfuerzo mayor en su trabajo, en sus labores, es un completo reajuste, un nuevo rol y función.

De todos los roles evidenciados en el análisis de la investigación consideramos que el rol materno es el más integral ya que las madres logran asumir varios roles a la vez como son: Proveer, cuidar, ejercer autoridad y lo más importante brindar afecto, aunque son varios su roles, las madres se preocupan por el bienestar emocional de sus hijos, lo cual es importante en la crianza de sus hijos; algunas entrevistas muestran que luego de la migración la relación conyugal termina, lo que obliga a la madre no solo a ejercer un rol materno sino un rol paterno, como diría una de las entrevistadas "Soy el hombre de la casa" pues algunos no volvieron a aparecer, pues restablecieron sus vidas en el país de migración. 
Según Puyana, (2000) nos da entender el significado de maternidad:

La maternidad construye representaciones sociales que condensan las ideas que la sociedad genera al respecto. Así se mezclan imágenes, percepciones, sentimientos que orientan las prácticas de las personas en la vida cotidiana y al mismo tiempo son interiorizadas por cada ser, formando parte de su universo simbólico. $(p, 90)$

Como lo afirma el autor en el párrafo anterior, el significado del rol materno se ha constituido de conformidad con los imaginarios y los estereotipos de la misma sociedad, como, por ejemplo: $\mathrm{Ha}$ sido atribuido al género femenino quien se dedica a la crianza y al cuidado de los hijos y esto lo podemos constatar en las entrevistas realizadas.

A diferencia del rol paterno, las madres entrevistadas cultivan lazos fuertes de afecto con sus hijos, estos logran fortalecerse cuando el padre migra, pues se vuelve un esfuerzo mutuo y recíproco, los cambios estructurales familiares obligan a la familia a tomar decisiones sobre los cambios de los roles, como expresa una madre:

"María" afirma que: "El rol que yo tenía de madre lo tomó mi madre y ella es la mamá para mis hijos porque siempre está pendiente de ellos en todo momento, mis hijos no le dicen abuela sino mamá" (Entrevistada, 2015).

Los cambios que deja la migración de sus esposos en la crianza de sus hijos son entonces el asumir nuevos roles y funciones dentro del hogar en ausencia del padre, como son la autoridad, el establecimiento de normas y castigos, el rol de proveeduría, entre otros. Aunque la persona que queda en su país de origen sostiene comunicación con el migrante sobre todo para el tema de comportamientos, normas y castigos, es finalmente la persona que está con los hijos quien las define, cuando se trata de hijos adolescentes ya no se recurre a la corrección física, sino que como dijo una madre en una entrevista: "Se trata de una negociación”, llegar a acuerdos, quitar pasatiempos, salidas y gustos. (Entrevistada, 2015).

Para los casos donde la madre es quien migra, son ellas quienes cultivan esas relaciones afectivas, a pesar de la distancia, la comunicación es mucho más frecuente que cuando migra el padre, las llamadas y conversaciones se nutren de muchas más palabras de afecto.

Al respecto, Pérez y Arrázola, (2013), indican que:

La familia es un sistema social donde con dinámica propia, espacio para el afecto y la participación a través de los roles conyugales, parentales y fraternales. Los vínculos afectivos son la expresión de la unión entre padres e hijos, aspecto que va más allá de la relación de parentesco y está presente en todas las tareas educativas, facilitando la comunicación familiar, la seguridad en los momentos difíciles, el establecimiento de normas y su cumplimiento. ( $p, 19$

La experiencia de la vida familiar trasnacional detona cambios en las relaciones a partir de cómo se conectan, estructuran y adquieren solidez o no los vínculos emocionales y afectivos entre padre, madre e hijos, hermanos y la red parental extensa que se activa antes y durante el proceso migratorio. $(\mathrm{p}, 157)$

En lo planteado anteriormente, el cuidado de los hijos es asumido generalmente por las abuelas o las tías, asegurando su salud, bienestar, formación académica, alimentación y afecto, todo esto de acuerdo a las indicaciones de la madre en la distancia. Son pocos los padres que se quedan y asumen el rol materno.

En una de las entrevistas aplicadas, a la pregunta ¿Cómo se establecían las normas en su familia y quién las determinaba?, el entrevistado respondió: "Mira, cuando estaba con mi esposa era yo quien las establecía, mmmmmm (...) pero al viajar las 
asumió mi esposa, sobretodo en la crianza de Juan Alejandro, nuestro hijo, ya que yo no puedo estar mmmmmmm (triste) de manera presencial con él (Entrevistado 2015).

\section{Rol de conyugalidad}

Gervilla (2003) indica que: "las familias y sus relaciones se cimientan en el compromiso de convivencia y de entrega mutua entre hombre y mujer, para cumplir la doble finalidad de la sexualidad: agrado sensual mutuo y procreación de los hijos" (p.32).

De acuerdo con la anterior definición, es claro que este rol se deteriora o se fragmenta por la distancia y la migración.

Por otro lado, según Ariza y D’Aubeterre (citado por Cienfuegos, 2011) nos indica que:

El distanciamiento espacial en la vivencia del lazo conyugal abre un espacio de incertidumbre en el horizonte familiar y replantea las fronteras habituales de la convivencia del grupo (...) trastoca al mismo tiempo dimensiones cruciales de la vida familiar como la socialización y educación de los hijos, el ejercicio de la paternidad y maternidad, la afectividad, la sexualidad y hasta las pautas de sociabilidad, que han de buscar -cuando se pueda- cauces alternativos de expresión. (p, 166)

Se evidencia a través de las entrevistas que la migración genera en gran parte de los casos estudiados que las relaciones de conyugalidad se distancian y en otros casos se rompen, así como también se generan innumerables conflictos por la crianza de los hijos sobre todo con quien migra, pues quien se queda se queja de su ausencia y su falta de colaboración en el tema de obediencia por parte de sus hijos.

En este sentido se reitera la importancia de tener lazos afectivos sólidos y establecer claramente las prioridades de la familia durante el proceso migratorio, pues la distancia generada por la migración puede desatar mayor unión o mayor separación.

Zelizer (citado por Sánchez, López y Palacio, 2013), plantea que la madre y el padre migrante centran su vínculo desde lo económico, ya que "En la vida cotidiana, la gente se desvela e invierte una gran cantidad de esfuerzo para encontrar el vínculo apropiado entre las relaciones económicas y los lazos de su vida privada" (p. 166).

Lo anterior refleja que, durante la migración, las prioridades de las familias y las parejas cambian. Dado que el principal motivo de migración es el económico, la búsqueda de mejores oportunidades para brindarles mejor calidad de vida a sus hijos, la familia centra su atención en la economía, sus vínculos giran en torno al aspecto económico, de hecho los principales conflictos entre las parejas empiezan a desatarse cuando quien migró no envía dinero, solo un 6\% dejó de enviar dinero, el dinero es durante la migración el tema principal en la comunicación, las llamadas telefónicas y los chats y esto hace que aspectos claves y trascendentales en la familia y la pareja como las relaciones afectivas y las demostraciones de afecto, se dejen de un lado llevando en algunos casos, al deterioro o el quebrantamiento.

En cuanto al tema de relaciones, como diría Bauman (citado por Vespucci, 2006). "La soledad provoca inseguridad, pero las relaciones no parecen provocar algo muy diferente" (p. 162). Lo que quiere decir, que las relaciones actuales se ven afectadas por la soledad en las familias trasnacionales, este factor de soledad se hace notorio por la distancia que se presenta a causa del fenómeno de la migración.

Para dar continuidad al rol de conyugalidad y enfocar este concepto en lo relacionado con las pautas de crianza, tema central del presente artículo, es importante abordar los términos de pautas, prácticas de crianza y género, los cuales 
permiten tener claro que la perspectiva de género ha construido sobre la sociedad creencias que se han convertido culturalmente en tradición.

Tenorio, (2006) afirma que:

Tradicionalmente, mientras los hombres trabajan para llevar al hogar el sustento, las mujeres se encargan de estar en el hogar y criar a los niños. No obstante, en algunas zonas urbanas las mujeres han tenido que salir a trabajar y ganar el sustento para sus hogares, lo que produce algunas diferencias en su imagen como mujer y en sus prácticas en el hogar. Estos cambios son inducidos por las transformaciones de la sociedad que conllevan variaciones en la constitución familiar, haciendo aparecer casos de familias donde la cabeza es sólo el padre o sólo la madre o familias recompuestas. $(\mathrm{p}, 5)$.

Por lo anterior, en este artículo es claro que para el $61 \%$ de los entrevistados, el patrón tradicional de género se mantiene, cuando el grupo familiar ha tomado la decisión de que uno de los dos padres migre, manteniendo la perspectiva de que el hombre es quien trabaja para llevar el sustento al hogar, mientras que la mujer es la encargada de criar a los hijos y mantener el hogar. La responsabilidad de las pautas de crianza de los hijos es compartida entre padres, sin embargo, al estar el padre en otro país, distanciado de sus hijos, esta función recae más sobre el rol femenino.

\section{Rol de Fratría}

Según Bono, López y Vadillo (2012), nos dan a entender lo que significa el rol de Fratría:

En castellano utilizamos la palabra hermano de una manera genérica sin dar importancia al género, así tomando como referencia a La Real Academia de la Lengua encontramos que la definición de hermano es: "Persona que con respecto a otra tiene el mismo padre y la misma madre, o solamente el mismo padre o la misma madre" (p.30).

De otro lado, para Fernández (2008) (como se citó en Bono, López, y Vadillo, 2012), el rol de fratria es:

El orden de nacimiento en la fratría es importante, no sólo desde el punto de vista de la autoimagen del sujeto atendiendo al lugar que ocupa, sino además por las aspiraciones y expectativas sobre los hijos que se formulan los padres. Según esto, no es lo mismo ser primogénito a ser el último de los hijos, cuando son varios, o ser hijo único, ya Freud (1916) afirmaba que "La posición del niño dentro de la serie de los hijos es un factor relevante para la conformación de su vida ulterior, y siempre es preciso tomarla en cuenta en la descripción de una vida. (p.39)

Los conceptos anteriores ratifican que los hermanos juegan un papel importante en la crianza de los hijos en ausencia de un padre o de una madre, sobre todo los hermanos mayores; en algunas de las respuestas dadas por los entrevistados, muestran que cuando el padre migra y existe un hermano mayor, en el caso de la investigación tres hijas apoyan a la madre o a la cuidadora con las funciones del rol paterno, como autoridad y cumplimiento de reglas, es quien respalda las decisiones del cuidador y en su ausencia es también quien se encarga del cuidado de los hermanos menores, las entrevistas dejan ver que son un gran apoyo para quienes se quedan.

\section{5, Rol filial}

Según Serrano (2007) no da a entender el concepto de filiación:

Es eminentemente una noción de derecho, es el lazo jurídico que une al hijo con su padre y 
con su madre. Se ha entendido también como el vínculo de parentesco de consanguinidad entre dos personas, en donde una es padre o madre de la otra. Si se establece solamente frente al primero se le llama paternidad y ante la segunda, maternidad. Se tiene entonces que, la filiación fundamenta las relaciones familiares, establece las relaciones de patria potestad, órdenes sucesorales, derecho alimentario, nacionalidad y autoridad de los padres. Dada la importancia de dichas relaciones originadas en la filiación, las normas que las reglamenta son de orden público, no susceptibles de ser modificadas por las partes. (p. 6)

Se evidenció en las entrevistas que, en cuanto al rol de filiación o autoridad familiar, cuando el $77 \%$ de personas que migra son los padres, las madres son quienes asumen el rol de autoridad al interior de hogar, sin embargo, consultan a los padres en la toma de decisiones con relación a las normas, reglas y castigos. Sin embargo, el impacto en los hijos cuando uno de los padres se encuentra en otro país se evidencia en el siguiente testimonio:

Hasta mi hijo Cristian perdió ese año de colegio porque era muy apegado a él, eso fue muy tenaz, muy muy duro para todos. (Entrevista 2015).

Para los casos donde los hijos quedan a cargo del cuidado de algún familiar, el rol de autoridad la tienen los familiares, esto se evidencia más en el caso en que las mujeres son las que migran, dado que son las personas que se encuentran en contacto físico permanentemente.

Cuando me fui deje a mis hijos muy pequeños sobre todo la niña. Quedaron a cargo de mi hermana menor viviendo en la casa paterna (...) la casa de mis padres. (Entrevista 2015).
Teniendo en cuenta que las pautas de crianza son uno de los factores principales de análisis es de gran importancia conocer y exponer el concepto:

Según, Ortega, Ovalle y Ramos (2014), las pautas de crianza tienen que ver con: $\mathrm{El}$ orden normativo (patrones, normas, costumbres, expectativas), que le dice al adulto qué se debe hacer frente al comportamiento de los niños. Se refiere a lo esperado en la conducción de las acciones hacia los niños.

Según Aguirre (2000), las pautas constituyen: El vínculo directo con las determinaciones culturales propias del grupo de referencia. Las pautas hacen referencia a cómo se espera que se comporten los niños y niñas y que están relacionadas con las determinaciones culturales propias del grupo de 24 referencia, y son válidas para un grupo social dependiendo de quién defina lo que es normal o valorado. (pp. 23-24)

Por lo anterior, es importante tener en cuenta que la familia como primer escenario donde realizan las primeras socializaciones, las pautas de crianza permiten mantener o reorganizar el grupo familiar, brindando protección y amor a cada integrante ya que la familia es multiplicadora de valores y costumbres para la sociedad. En algunos casos, especialmente donde migró el padre, la madre asumió la crianza de los hijos, los permisos, la concertación de reglas ya que para el padre era muy difícil asumir dicho papel.

Yo nunca quise imponer nada en mi casa, pero de una forma u otra las determinaba yo. Creo que eso es porque soy mayor que Claudia; entonces tenía un poco más de experiencia en muchas cosas, ahora yo trato de seguir manejando las cosas, pero desde acá es más difícil y por eso ahora mi esposa se ha encargado de las cositas que van saliendo con el diario vivir. (Entrevistado 2015). 
Se evidencia que como consecuencia de la distancia se genera el cambio de roles en el hogar y también afecta el vínculo entre padre e hijos, ya que este no se encuentra presente en el desarrollo de su ciclo vital, lo cual hace que sus hijos vean más cercana a la persona que está de manera presencial. En las entrevistas realizadas, el promedio en años de migración es aproximadamente de 12 años, esto puede dar cuenta de que efectivamente el ciclo vital en el que se encontraban los hijos cuando uno de los dos padres migró era el escolar y que por lo tanto luego de los años los roles cambian.

Expuestos los conceptos y análisis de: rol paterno, rol materno, rol de conyugalidad, rol filial, rol de fratría, crianza, pautas y demás, puede entreverse que el fenómeno de la migración indudablemente genera cambios importantes y trascendentales en las familias para un completo reajuste de su sistema familiar, los ajustes, se presentan en el cambio de roles, ya que la autoridad, cambia, quedando en cabeza del padre o la madre que se queda en el país de origen; en algunos casos las familias se fragmentan, porque el que migra muchas veces constituye una nueva familia.

\section{Conclusiones}

El fenómeno de la migración en cuanto a la crianza de los hijos, transforma la autoridad y toma de decisiones que se dan en la familia, especialmente cuando es el padre quien migra, lo que genera cambios en el rol paterno, especialmente en el tema de autoridad en la familia, la proveeduría y la toma de decisiones, así como en lo relacionado a las normas y pautas de crianza en los hijos. Antes de la migración, en algunos casos, el padre ejercía la autoridad en el hogar, proveía económicamente y participaba en la toma de decisiones; sin embargo, durante la migración, estas funciones del rol paterno cambian y es la madre quien las asume.
A pesar de las situaciones vividas se observa que, de acuerdo con los resultados de esta investigación, se logra mantener la comunicación, teniendo en cuenta que las familias al sufrir este fenómeno se ven enfrentadas a cambios estructurales familiares, donde los subsistemas conyugal y fraternal se fragmentan. En algunas entrevistas, los padres y madres migrantes iniciaron una nueva relación en el país de llegada, generando la separación con su esposa, o esposo, pero manteniendo el vínculo con sus hijos.

Es importante resaltar que el fenómeno familiar vivido desde la perspectiva de género, el hombre es quien migra, es decir que en la mayoría de los casos es el hombre quien se ve enfrentado a viajar en busca de las mejores condiciones para la familia. Por ende, la mujer es la encargada de asumir las funciones del hogar y el cuidado de los hijos, es de notar que no hay cambios en el patrón cultural, donde los hombres son los que trabajan y las mujeres son las que se dedican al hogar.

Por otro lado, la madre que asume el rol cuidador, muchas veces se ve en la obligación de buscar opciones laborales, lo que implica cambios estructurales que fragmentan las relaciones, cediendo roles en los que la abuela y en muchos casos los hijos adolescentes asumen el cuidado de los hermanos menores.

De conformidad con los casos estudiados para la presente ponencia, la crianza de los hijos sufre varios cambios sobre todo cuando se trata de hijos en edad escolar, ya que cuando uno de los padres migra, la autoridad y responsabilidad recae sobre una sola persona quien debe considerar nuevas estrategias, puesto que debido a la distancia con el padre que migró, en algunos casos los hijos no lo reconoces como autoridad.

El vínculo establecido entre los menores y el migrante se debilita con el paso del tiempo, surgen sentimientos y emociones como: alegría, esperanza, desolación, angustia por el ser querido 
que migró, lo que genera en el niño una serie de afectaciones emocionales que pueden llegar a influir en otros aspectos tales como el rendimiento escolar, las relaciones con sus pares y familiares.

La separación de uno de los miembros de la familia genera un quebranto emocional que conlleva a un proceso de duelo por la separación, en donde el quehacer de Trabajo Social juega un papel importante, pues aquí comienza el rol de acompañamiento con la persona que migró a otro país y la familia que se queda residiendo en Colombia; el profesional en este proceso, reconstruye y/o fortalece el vínculo de la familia en los diferentes roles, para disminuir el impacto que genera la migración, a través de diferentes técnicas y herramientas como por ejemplo genograma, ecomapas, visitas domiciliarias y entrevistas que en primera medida permiten determinar un diagnóstico, con el que se puede identificar en qué roles del vínculo familiar se debe realizar el fortalecimiento.

\section{Referencias}

Bono, L., López, I. y Vadillo. (2012). Diagnóstico y posición en la fratría. Recuperado de: http://www.avntf- vntf.com/ imágenes/biblioteca/Trabajo/Vadillo.pdf

Cifuentes G. (2011). Diseño de Proyectos de Investigación Cualitativa. Buenos Aires, Argentina.- México: Noveduc.

Cienfuegos, I. J (2011). Desafíos y continuidades en la conyugalidad a distancia. Estudios de Familia. 3

Gervilla. E. (2003). Educación familiar, nuevas relaciones humanas y humanizadoras. Madrid- España. Recuperado de: https:/dialnet.unirioja.es/servlet/ libro? codigo $=9610$.

Guarnizo, L.E. (2006). Migración, globalización y sociedad: teorías y tendencias en el siglo XX. En: Ardila. G. Colombia:migraciones, transnacionalismo y desplazamiento. Bogotá: Universidad de Colombia. Recuperado de: http://www.bdigital.unal.edu.co/785/3/257_-_2_ Capi_1.pdf
Micolta, A. A (2002). La paternidad como parte de la identidad masculina. Recuperado de: bibliotecadigital.univalle.edu.co/.../Prospectiva\%206\%20y\%207.pdf

Ortega, D., Ovalle, R. y Ramos, G. (2014). Dinámica en las pautas y prácticas de crianza de una familia monoparental del barrio Charco Azul, en la ciudad de Cali. (tesis de pregrado) Universidad Abierta y a Distancia. Palmira. Colombia: Recuperado de: http:// stadium.unad.edu.co/preview/UNAD.php?url=/bitstream/10596/3384/4/1130584422.pdf

Pérez, C. y Arrázola, E. (2013). Vínculo afectivo en la relación parento- filial como factor de calidad de vida. Tendencias \& Retos. 18, (1). Bogotá: Ediciones Unisalle.

Puyana, V. (2000). Ética: Masculinidades y Feminidades. Recuperado de: http://www.bdigital.unal.edu. co/1236/2/01PREL01.pdf

Micolta, L. y Palacio, M. (2013). Familias Colombianas y migración internacional: entre la distancia y la proximidad. Bogotá: Editorial Centro de estudios Sociales (CES) - Facultad de Ciencias Humanas de la Universidad Nacional de Colombia: 165- 166

Rivera, R y Ceciliano, Y. (2004). Cultura, Masculinidad y Paternidad: las representaciones de los hombres en Costa Rica.

Recuperado de: http://www.cepal.org/mexico/publicaciones/sinsigla/xml/9/22699/masculinidad,unfpa flacsocepalcasc2.pdf

Serrano, L (2007). La filiación y sus acciones en la Ley 1060. Revista Virtual Vía Inveniendi Et Iudicandi. Camino del Hallazgo y del Juicio. Recuperado de: http:// numanterioresviei.usta.edu.co/articulos/edi4/filiacionley-1060.pdf

Tenorio, M.C., (2006). Pautas y prácticas de crianza en familias colombianas. Bogotá: Ministerio de Educación y Organización de Estados Americanos.

Recuperado de: http://pautasdecrianza.org/descargas/Folleto-Pautas-practicas-crianza2.pdf

Vespucci, G. (2005). Amor Líquido. La fragilidad de los vínculos humanos. Acerca de los vínculos humanos. Revista Argentina de Sociología. 4 (6): 162. Recuperado de: http://www.redalyc.org/pdf/269/26940608.pdf 